\title{
Use of immune checkpoint inhibitors in patients with solid tumors and pre-existing autoimmune or inflammatory disease: real-word data.
}

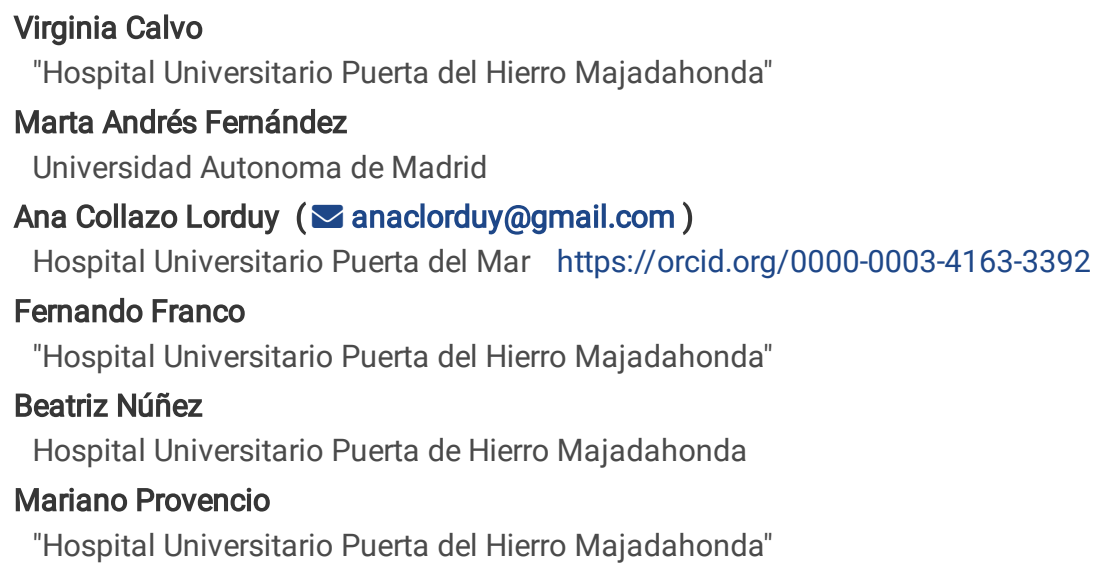

Version of Record: A version of this preprint was published at Lung Cancer Management on July 2nd, 2021. See the published version at https://doi.org/10.2217/Imt-2021-0003. 


\section{Abstract OBJECTIVE}

Immune checkpoint inhibitors (ICI) are a cornerstone in cancer treatment but they can induce immune-related adverse events (irAEs). Furthermore, patients with pre-existing autoimmune and/or inflammatory disease (AID) have been excluded from clinical trials. The objective of this study is to evaluate the efficacy and safety of ICI in patients with cancer and AID.

\section{METHODS}

This is an observational, retrospective study carried out at the Medical Oncology Department of Hospital Universitario Puerta de Hierro, Majadahonda, Madrid between January 2016 and December 2018.

\section{RESULTS}

202 cancer patients treated with ICl were included, $15(7,4 \%)$ of them had pre-existing autoimmune diseases. The most frequent pre-existing AID were thyroid diseases (33.3\%): autoimmune hypothyroidism, Graves Basedow disease and Hashimoto's thyroiditis. Three patients had psoriasis, two ANA + polyarthritis, one rheumatoid arthritis, another LADA (latent autoimmune diabetes in adults), another a systemic lupus erythematosus (SLE) and the last one, a polymyalgia rheumatica. In this series, the majority of patients (73.33\%) did not experience any flareup of their autoimmune disease. In patients who had AID flare-up, this was treated with corticosteroids. The most frequent cause of immunotherapy discontinuation was tumor progression (40\%). $20 \%$ of patients had to discontinue immunotherapy due to toxicity.

\section{CONCLUSIONS}

In our series, AID flare or irAEs in patients with pre-existing AID who receive immunotherapy are not very common and can often be controlled without interrupting treatment. Prospective studies are needed to establish the incidence of irAEs in patients with preexisting autoimmune conditions, evaluate risk-benefits and elaborate management clinical guidelines in this population.

\section{Background}

\section{BACKGROUND}

Immune checkpoint inhibitors (ICI) have revolutionized (dramatically changed) cancer treatment and are becoming a standard of care in different types of cancer. ICl include anti-programmed cell death 1 (anti-PD-1) agents (nivolumab, pembrolizumab), anti-programmed cell death-ligand 1 (anti-PD-L1) agents (atezolizumab, durvalumab, avelumab), and cytotoxic T lymphocyte-associated protein 4 inhibitors (antiCTLA-4) like ipilimumab and tremelimumab. ICI have been approved for the treatment of multiple advanced solid tumors, including melanoma, non-small cell lung cancer (NSCLC) and, urothelial cancer. In many other pathologies, these drugs are under investigation in other settings such as neoadjuvant and adjuvant treatments.

Ipilimumab, an anti-CTLA-4 antibody, was the first ICI approved by health authorities as a treatment for metastatic melanoma in patients without prior treatment, in 2011. After this, it has been studied in other types of tumors, such as non-small cell lung cancer (NSCLC) or renal cell carcinoma. Ipilimumab was followed by antibodies that block PD-1 and PD-L1; the first of these was pembrolizumab, an anti-PD-1 antibody approved in 2014 for the treatment of metastatic melanoma that was later also approved for NSCLC'. Nivolumab, another anti-PD-1, was initially approved for the treatment of melanoma, NSCLC', and renal cell carcinoma. Atezolizumab is the only anti-PD-L1 and was approved in 2016 for the treatment of urothelial carcinoma. Later, these PD-1 / PD-L1 blocking antibodies have been shown to be effective in other types of tumors, such as head and neck cancer, Hodgkin lymphoma, hepatocellular carcinoma (HCC) or gastric cancer.

Since the mechanism of action is different, its combination has been studied and shown to have a synergistic effect, obtaining better results than monotherapy in melanoma. The combination of ipilimumab with nivolumab was approved by the FDA in 2015 for the treatment of advanced melanoma and has also been studied in the treatment of NSCLC with promising results. The development of ICI as a cancer treatment has brought with it the appearance of new toxicities, related to the activation of the immune system. These toxicities are known as immune-related adverse events (irAEs). The most frequent adverse effects are cutaneous, gastrointestinal, respiratory and endocrine (especially affecting the thyroid gland). These inflammatory and/or autoimmune manifestations are frequent, up to $70 \%$ for anti PD-1 and up to $90 \%$ for anti CTLA-4. A recent meta-analysis has found that anti CTLA-4 treatment causes high grade irAEs in approximately $20-30 \%$ of patients. Meanwhile, anti PD-1 treatment causes high grade irAEs in less than $5 \%$. Due to the appearance of these irAEs, patients with 
autoimmune diseases have been frequently excluded from clinical trials with ICI. For this reason, there is very little evidence about the impact that having a pre-existing autoimmune disease can have on the selection, toxicity or efficacy of immunotherapy treatment.

Despite this, some studies show that although these patients often have exacerbations of their pre-existing autoimmune disease, they can be easily managed, benefiting from the anti-tumor effect of ICl. These studies therefore suggest that by balancing the overall risk-benefits patients with pre-existing autoimmune diseases can benefit from immunotherapy treatment.

The objective of this study is to evaluate the efficacy and safety of ICI in patients with cancer and pre-existing AID.

\section{Material And Methods STUDY DESIGN}

This is an observational, retrospective and single-center study, carried out at the Medical Oncology Department of Hospital Universitario Puerta de Hierro, Majadahonda, Madrid. The list of patients was obtained through the HUPHM Pharmacy Service and it included all patients treated with immunotherapy (nivolumab, pembrolizumab, atezolizumab or ipilimumab) at the Medical Oncology Service of these hospital, between January 2016 to December 2018, inclusive. This sample includes patients treated with immunotherapy (according to protocol) or within a clinical trial. 206 were reviewed (electronic medical record), of which 4 were excluded because they did not meet the inclusion criteria.

\section{VARIABLES}

Different variables were collected: age, sex, type of cancer, tumor stage, date of diagnosis, previous treatments, immunotherapy treatment, start date, end date, reason for discontinuation, immune-related adverse effects, date of last follow-up or date of exitus.

Regarding the history of autoimmune disease, the following data have been collected: type of autoimmune disease, date of diagnosis, treatment and evolution of autoimmune diseaseafter treatment with immunotherapy.

\section{CONFIDENTIALITY OF DATA}

Both data collection and analysis have been carried out anonymously at all times, taking appropriate precautions to maintain patient confidentiality.

This work has been classified by the Spanish Agency of Medicines and Health Products (AEMPS) as a post-authorization study with other designs different from the prospective follow-up (abbreviated as EPA-OD), and has the favorable opinion of the Ethical Committee for Research with Medicines of the HUPHM and the Ethics Subcommittee of the Autonomous University of Madrid.

\section{ANALYSIS}

Statistical analysis was carried out using SPSS v25.

\section{Results}

206 medical records of patients treated with immunotherapy (nivolumab, pembrolizumab, atezolizumab or ipilimumab) were reviewed in the Medical Oncology Service, of the HUPHM, between January 2016 and December 2018, both included. Of these, 4 were excluded because they did not meet the inclusion criteria, they had been treated with several immunotherapy drugs during the course of the disease and this could confound our results. Of the 202 patients diagnosed with cancer and treated with immunotherapy (monotherapy or in combination) at a certain point in the course of their disease, 15 were found to have a history of autoimmune disease (7.4\%). The characteristics of these 15 patients are described in Table 1. 
Table 1

Characteristics of patients with previous autoimmune disease

\begin{tabular}{|c|c|c|c|c|c|c|c|c|}
\hline Patient & AID & Tumor & $\mathrm{ICI}$ & $\begin{array}{l}\text { Line of } \\
\text { treatment }\end{array}$ & $\begin{array}{l}\text { Treatment } \\
\text { duration }\end{array}$ & Discontinuation & $\begin{array}{l}\text { Evolution } \\
\text { AID }\end{array}$ & Exitus \\
\hline 1 & $\begin{array}{l}\text { Autoimmune } \\
\text { hypothyroidism }\end{array}$ & $\begin{array}{l}\text { Renal cell } \\
\text { carcinoma }\end{array}$ & Atezolizumab & 2 & 9 weeks & Toxicity & Exacerbation & NO \\
\hline 2 & $\begin{array}{l}\text { Autoimmune } \\
\text { hypothyroidism }\end{array}$ & Hepatocarcinoma & Nivolumab & 1 & 4 weeks & Toxicity & No changes & YES \\
\hline 3 & $\begin{array}{l}\text { Graves } \\
\text { Basedow } \\
\text { disease }\end{array}$ & $\begin{array}{l}\text { Lung cancer: } \\
\text { Adenocarcinoma }\end{array}$ & Pembrolizumab & 1 & 6 weeks & Progression & No changes & NO \\
\hline 4 & $\begin{array}{l}\text { Graves } \\
\text { Basedow } \\
\text { disease }\end{array}$ & Hepatocarcinoma & Nivolumab & 2 & 15 weeks & Exitus & Exacerbation & YES \\
\hline 5 & $\begin{array}{l}\text { Hashimoto } \\
\text { thyroidis }\end{array}$ & Melanoma & $\begin{array}{l}\text { Nivolumab + } \\
\text { Ipilimumab }\end{array}$ & 1 & $\begin{array}{l}33 \\
\text { months }\end{array}$ & & No changes & NO \\
\hline 6 & Psoriasis & $\begin{array}{l}\text { Lung cancer: } \\
\text { Adenocarcinoma }\end{array}$ & Nivolumab & 1 & $\begin{array}{l}12 \\
\text { months }\end{array}$ & Toxicity & Exacerbation & NO \\
\hline 7 & Psoriasis & $\begin{array}{l}\text { Lung cancer: } \\
\text { Adenocarcinoma }\end{array}$ & $\begin{array}{l}\text { Nivolumab + } \\
\text { Carboplatino/ } \\
\text { Paclitaxel }\end{array}$ & 1 & $\begin{array}{l}14 \\
\text { months }\end{array}$ & & No changes & NO \\
\hline 8 & Psoriasis & $\begin{array}{l}\text { Lung cancer: } \\
\text { Squamous cell } \\
\text { carcinoma }\end{array}$ & Nivolumab & 1 & $\begin{array}{l}12 \\
\text { months }\end{array}$ & Progression & No changes & NO \\
\hline 9 & $\begin{array}{l}\text { ANA + } \\
\text { Polyarthritis }\end{array}$ & $\begin{array}{l}\text { Lung cancer: } \\
\text { Adenocarcinoma }\end{array}$ & Pembrolizumab & 1 & 6 weeks & & Exacerbation & NO \\
\hline 10 & $\begin{array}{l}\text { ANA + } \\
\text { Polyarthritis }\end{array}$ & Timoma & Pembrolizumab & 2 & 3 weeks & Progression & No changes & YES \\
\hline 11 & $\begin{array}{l}\text { Rheumatoid } \\
\text { arthritis }\end{array}$ & $\begin{array}{l}\text { Lung cancer: } \\
\text { Adenocarcinoma }\end{array}$ & Nivolumab & 2 & $\begin{array}{l}14 \\
\text { months }\end{array}$ & Exitus & No changes & YES \\
\hline 12 & $\begin{array}{l}\text { LADA type } \\
\text { diabetes }\end{array}$ & Melanoma & $\begin{array}{l}\text { Nivolumab + } \\
\text { Ipilimumab }\end{array}$ & 5 & 13 weeks & Progression & No changes & NO \\
\hline 13 & $\begin{array}{l}\text { Systemic lupus } \\
\text { erythematosus }\end{array}$ & $\begin{array}{l}\text { Renal cell } \\
\text { carcinoma }\end{array}$ & Nivolumab & 2 & 7 months & Progression & No changes & NO \\
\hline 14 & $\begin{array}{l}\text { Polymyalgia } \\
\text { rheumatica }\end{array}$ & Hepatocarcinoma & Nivolumab & 1 & $\begin{array}{l}18 \\
\text { months }\end{array}$ & & No changes & NO \\
\hline 15 & $\begin{array}{l}\text { Antinuclear } \\
\text { antibodies+ } \\
\text { (ENA, DNA) }\end{array}$ & Hepatocarcinoma & Nivolumab & 1 & 8 months & Progression & No changes & YES \\
\hline
\end{tabular}

A broad spectrum of pre-existing autoimmune disease was reported. 5 patients (33\%) had a history of autoimmune thyroid disease, 2 (13\%) patients had a history of autoimmune hypothyroidism, 2 (13\%) of Graves Basedow disease and 1 (7\%) of Hashimoto thyroiditis. 3 (20\%) patients had psoriasis, 2 (13\%) ANA + polyarthritis, 1 (7\%) rheumatoid arthritis, 1 (7\%) LADA type diabetes, another Systemic Lupus Erythematosus (SLE) and another, polymyalgia rheumatica. The last case was a patient with positive antinuclear antibodies but without established diagnosis.

Most of the patients (73.33\%), did not experience any change or exacerbation of their autoimmune disease during immunotherapy treatment, 4 (27\%) of them had a worsening of prior manifestations.

The most frequent cause of discontinuation of immunotherapy treatment was the progression of tumor disease (40\%), 5 patients of them died (33.3\%). Only 3 of the 15 patients (20\%) had to discontinue immunotherapy due to toxicity. In 2 of these patients, the toxicity was related to a 
worsening of prior manifestations of the pre-existing autoimmune disease (psoriasis in one case and autoimmune hypothyroidism in another), while the toxicity of the third patient, hepatotoxicity, was not related to his underlying autoimmune disease (autoimmune hypothyroidism).

Finally, it is important to note that 5 of the 15 patients (33.3\%) did not present any immune-related adverse reaction, although 2 of these 5 patients experienced a worsening of their underlying disease.

Of the 202 patients, $114(56.4 \%)$ experienced some immune-related adverse event. Of those, $58(50.9 \%)$ experienced only one, $33(28.9 \%)$ experienced two, and $23(20.2 \%$ ) experienced 3 or more (up to 6 ).

Because the degree of toxicity was not well recorded in the medical records in all cases, we considered serious immune-related adverse events those requiring hospital admission and / or interruption of immunotherapy treatment. Of the 114 patients who presented any irAEs, 24 had to discontinue immunotherapy (11.9\%). Of these 24 patients who had severe irAEs, 12 were receiving Nivolumab as monotherapy and 7 Nivolumab + Ipilimumab.

Table 2 shows the different immune-related adverse events that appeared with the different treatment schedules

Table 2

Immune-related adverse events

\begin{tabular}{|c|c|c|c|c|c|c|c|}
\hline irAEs & $\begin{array}{l}\text { Nivolumab } \\
(\mathrm{N}=124)\end{array}$ & $\begin{array}{l}\text { Pembrolizumab } \\
(\mathrm{N}=26)\end{array}$ & $\begin{array}{l}\text { Atezolizumab } \\
(\mathrm{N}=10)\end{array}$ & $\begin{array}{l}\text { Ipilimumab } \\
(\mathrm{N}=5)\end{array}$ & $\begin{array}{l}\text { Nivolumab } \\
+ \\
\text { Ipilimumab } \\
(\mathrm{N}=24)\end{array}$ & $\begin{array}{l}\text { Nivolumab } \\
+ \\
\text { Daratumumab } \\
(\mathrm{N}=6)\end{array}$ & $\begin{array}{l}\text { Nivolumab + } \\
\text { Carboplatino/ } \\
\text { Paclitaxel ( } \mathrm{N}= \\
7)\end{array}$ \\
\hline Asthenia & $22(17.7 \%)$ & $12(46.2 \%)$ & 0 & 0 & $2(8.3 \%)$ & $1(16.7 \%)$ & $3(42.9 \%)$ \\
\hline Hyporexia & $1(0.8 \%)$ & $3(11.5 \%)$ & 0 & 0 & 0 & 0 & 0 \\
\hline Rash & $4(3.2 \%)$ & $2(7.7 \%)$ & $1(10 \%)$ & $2(40 \%)$ & $5(20.8 \%)$ & 0 & $2(28.6 \%)$ \\
\hline Pruritus & $6(4.8 \%)$ & $4(15.4 \%)$ & 0 & 0 & $6(25 \%)$ & $1(16.7 \%)$ & $2(28,6 \%)$ \\
\hline Vitiligo & $1(0.8 \%)$ & 0 & 0 & 0 & $1(4.2 \%)$ & 0 & 0 \\
\hline Psoriasis & $1(0.8 \%)$ & 0 & 0 & 0 & $1(4.2 \%)$ & 0 & $1(14.3 \%)$ \\
\hline Infusional reaction & $1(0.8 \%)$ & 0 & 0 & 0 & $1(4.2 \%)$ & 0 & 0 \\
\hline Diarrhea/Colitis & $3(2.4 \%)$ & $4(15.4 \%)$ & 0 & 0 & $4(16.7 \%)$ & 0 & 0 \\
\hline $\begin{array}{l}\text { Nausea/ } \\
\text { Vomiting }\end{array}$ & $2(1.6 \%)$ & $1(3.8 \%)$ & 0 & 0 & 0 & 0 & $1(14.3 \%)$ \\
\hline Liver toxicity & $9(7.3 \%)$ & $2(7.7 \%)$ & $1(10 \%)$ & 0 & $6(25 \%)$ & 0 & 0 \\
\hline Pancreatic toxicity & $3(2.4 \%)$ & 0 & 0 & 0 & $1(4.2 \%)$ & 0 & 0 \\
\hline Pneumonitis & 7 (5.6\%) & $2(7.7 \%)$ & 0 & 0 & $5(20.8 \%)$ & 0 & 0 \\
\hline Arthritis & $5(4 \%)$ & $3(11.5 \%)$ & $1(10 \%)$ & 0 & 0 & 0 & $1(14.3 \%)$ \\
\hline Neurotoxicity & $5(5 \%)$ & $1(3.8 \%)$ & 0 & 0 & 0 & 0 & 0 \\
\hline Anemia & $2(1.6 \%)$ & 1 (3.8\%) & 0 & 0 & 0 & 0 & 0 \\
\hline Neutropenia & $3(2.4 \%)$ & $2(7.7 \%)$ & 0 & 0 & 0 & 0 & 0 \\
\hline Thrombopenia & $1(0.8 \%)$ & $1(3.8 \%)$ & 0 & 0 & 0 & 0 & 0 \\
\hline Renal toxicity & $1(0.8 \%)$ & $1(3.8 \%)$ & 0 & 0 & $2(8.3 \%)$ & $1(16.7 \%)$ & 0 \\
\hline Thyroid toxicity & $16(12.9 \%)$ & $2(7.7 \%)$ & $1(10 \%)$ & 0 & $3(12.5 \%)$ & $1(16.7 \%)$ & $1(14.3 \%)$ \\
\hline Parathyroid toxicity & $1(0.8 \%)$ & 0 & 0 & 0 & 0 & 0 & 0 \\
\hline Mellitus diabetes & 0 & $1(3.8 \%)$ & 0 & 0 & $2(8.3 \%)$ & 0 & 0 \\
\hline $\begin{array}{l}\text { Suprarrenal } \\
\text { insufficiency }\end{array}$ & $1(0.8 \%)$ & 0 & 0 & 0 & $1(4.2 \%)$ & 0 & 0 \\
\hline Others & $3(2.4 \%)$ & 0 & 0 & 0 & $2(8.3 \%)$ & 0 & $1(14.3 \%)$ \\
\hline
\end{tabular}




\section{Discussion}

Immune checkpoint inhibitors (ICI) represent an important new treatment modality for cancer patients. Despite the important clinical benefits of ICI therapy, these treatments can also cause a variety of immune-related adverse events (irAEs). The mechanisms leading to irAEs are unclear, although irAEs caused by ICI resemble autoimmune disease. That's the reason why all the clinical trials leading to the approval of ICI therapy actively excluded patients with preexisting active autoimmune disease because of apprehension that these individuals might be at risk for treatment induced irAEs.

The objective of this observational study of patients with cancer and preexisting autoimmune disease (AD) is to evaluate the efficacy and safety of ICl.

Many patients who are diagnosed with cancer have a preexisting autoimmune disease, for example, approximately $14-25 \%$ of patients with lung cancer also have an AID. However, in our series only $7.4 \%$ of patients with cancer treated with ICI had a preexisting AID. This low prevalence in our sample may be due to several factors. Firstly, the use of immunotherapy in patients with preexisting autoimmune disease is not very widespread due to the lack of experience. The increased risk of irAEs, which can be unpredictable and potentially very serious, and the risk of AID symptom exacerbation (flare-ups) in patients with preexisting AID has led these patients to be frequently excluded from immunotherapy clinical trials. For this reason, there is very little evidence and very little clinical experience in the use of immunotherapy in these patients. Secondly, our sample includes patients receiving immunotherapy within a clinical trial, whose exclusion criteria include suffering or having some autoimmune-based pathology.

In our study, we found that 4 of the 15 patients (26.67\%) with preexisting AID had autoimmune exacerbations. This percentage was lower to that observed in other series. Johnson et al retrospectively evaluated 30 patients with preexisting autoinmune disease and metastatic melanoma. Of the 30 patients who received ipilimumab, 15 (50\%) experienced irAEs or flares of their underlying autoimmune disease. Leonardi et al ${ }^{13}$ retrospectively analyzed the safety of anti-PD-1 and PD-L1 antibodies (nivolumab, pembrolizumab, or atezolizumab) in 56 patients with non-small-cell lung cancer (NSCLC) and preexisting autoimmune disease. $55 \%$ of patients developed a flare and/or irAEs. Danlos et al compared 45 patients with underlying $A D$ to 352 patients without AD who were treated with anti-PD-1 agents in the Registry of Severe Adverse Reactions to Immunomodulatory Antibodies Used in Oncology (REISAMIC) between 2014 and 2016. $47.1 \%$ of the patients with AD experienced an $A D$ flare, $65.9 \%$ experienced an irAEs, and $9.4 \%$ developed a grade $3 / 4$ irAEs. In a recent review of 41 case reports published to date, in $65.6 \%$ of patient immunotherapy resulted in a flare-up of the baseline disease; being severe and very severe in $22.7 \%$ of patients.

Of the 4 patients in our study with preexisting AID that had flares, one was treated with atezolizumab, two with nivolumab, and one with pembrolizumab, so we cannot think that a certain drug could interfere with previous AID more than another.

The most frequent cause of discontinuation of immunotherapy was not immune-related adverse events, as we might expect from patients with preexisting AID, it was progression of tumor disease (40\%). Only 3 of the 15 patients $(20 \%)$ had to discontinue immunotherapy for toxicity. Despite the fact that five patients died during our follow-up period, no deaths occurred as a consequence of treatment.

On the other hand, although it is true that irAEs occurred (not related to preexisting AID) in 10 of the 15 patients (66.7\%), most were mild and easy to control. Of the 5 patients (33.3\%) who did not have any irAEs, two experienced worsening of their disease. Three patients (20\%) did not present any immune-related adverse event or not to their pre-existing AID. The incidence of irAEs observed in Johnson et al. did not exceed the incidence of irAEs found by other studies in a population without AID. In our study, $66.7 \%$ of patients with AID present irAEs.

Despite the limited information in this regard, some studies have concluded that ICI can be used in patients with previous AID, since the potential risks do not seem to outweigh the benefit of these treatments.

Khan SA and collaborators observed that AID were relevant in NSCLC, $14 \%$ of patients with NSCLC had a concurrent AID and they could be treated with $\mathrm{ICl}$, since they observed that patients with AID present a mortality from cancer and from any cause similar to those patients who do not have AID. In patients with melanoma and AID, Johnson DB et al. ${ }^{14}$ concluded that ipilimumab treatment can be considered, always leading to close surveillance and monitoring of the patient, and the Menzies et al. study obtained a similar conclusion regarding anti-PD1 therapy.

\section{Conclusions}

In our series, exacerbations or irAEs in patients with prior autoimmune disease receiving immunotherapy treatment are not very common and can often be controlled without interruption of treatment. Administration of immunotherapy in cancer patients with a preexisting controlled autoimmune condition seems safe with an adequate follow-up and early onset of treatment once flares-up or irAES happen. 
Prospective studies are needed to establish the incidence of irAEs in patients with preexisting autoimmune conditions, evaluate the risk-benefit indexes, and elaborate management clinical guidelines in this population.

\section{Abbreviations}

$\mathrm{ICl}$

immune checkpoint inhibitors

irAES

immune related adverse events

AID

autoimmune inflammatory disease

LADA

latent autoimmune diabetes in adults

SLE

systemic lupus erythematosus

NSCLC

non-small cell lung cancer

$\mathrm{HCC}$

hepatocellular carcinoma

FDA

US Food and Drug administration

HUPHM

Hospital Universitario Puerta de Hierro Majadahonda

AEMPS

Spanish Agency of Medicines and Health Products

$A D$

autoimmune disease

\section{Declarations}

\section{- Ethics approval and consent to participate:}

- This study has the favorable opinion of the Ethical Committee for Research with Medicines of the HUPHM and the Ethics Subcommittee of the Autonomous University of Madrid.

- Consent for publication :

- Institutional consent for publication was obtained

- Availability of data and materials:

- The datasets used and/or analysed during the current study are available from the corresponding author on reasonable request.

- Competing interests:

- No conflicts of interests regarding this work need to be declared

\section{- Funding:}

This paper is part of a project that has received funding from the European Union's Horizon 2020 research and innovation program under grant agreement NO 875160

\section{- Authors' contributions:}


VC analyzed and interpreted the patient data regarding the autoimmune diseases and the adverse events and wrote the article; MF collected al the data, AC was a major contributor in writing the manuscript. FF contributed to the clinical interpreation of data, BN collected data and helped with the writing, MP contributed to the design and final interpretation. All authors read and approved the final manuscript."

\section{- Acknowledgements:}

- We would like to acknowledge all the patients in our Service who were treated with immunotherapy having a preexisting autoimmune disease for their confidence in our good clinical management.

\section{References}

1. Hodi FS, O’Day SJ, McDermott DF, Robert W Weber, Jeffrey A Sosman, John B Haanen, et al. Improved survival with ipilimumab in patients with metastatic melanoma. N Engl J Med 2010; 363: 711-23.

2. Robert C, Schachter J, Long GV, Ana Arance, Jean Jacques Grob, Laurent Mortier, et al. Pembrolizumab versus ipilimumab in advanced melanoma. N Engl J Med 2015; 372: 2521-32.

3. Garon EB, Rizvi NA, Hui R, Natasha Leighl, Ani S Balmanoukian, Joseph Paul Eder et al. Pembrolizumab for the treatment of non-small cell lung cancer. N Engl J Med 2015; 372: 2018-28.

4. Reck M, Rodríguez-Abreu D, Robinson AG, Rina Hui , Tibor Csoszi , Andrea Fülöp' et al. Pembrolizumab versus chemotherapy for PD-L1positive non-small cell lung cancer. N Engl J Med 2016; 375: 1823-33.

5. Robert C, Long GV, Brady B, Caroline Dutriaux, Michele Maio, Laurent Mortier, et al. Nivolumab in previously untreated melanoma without BRAF mutations. N Engl J Med 2015; 372(4):320-30.

6. Borghaei H, Paz-Ares L, Horn L, David R Spigel, Martin Steins, Neal E Ready et al. Nivolumab versus docetaxel in advanced nonsquamous non-small cell lung cancer. N Engl J Med 2015; 373: 1627-39.

7. Brahmer J, Reckamp KL, Baas P, Lucio Crinò, Wilfried E E Eberhardt, Elena Poddubskaya, et al. Nivolumab versus docetaxel in advanced nonsquamous non-small cell lung cancer. N Engl J Med 2015; 373: 123-35.

8. Motzer RJ, Escudier B, McDermott DF, Saby George, Hans J Hammers, Sandhya Srinivas, et al. Nivolumab versus everolimus in advanced renal-cell carcinoma. N Engl J Med 2015; 373: 1803-13.

9. Powles T, Duran I, van der Heijden MS, Yohann Loriot, Nicholas J Vogelzang, Ugo De Giorgi, et al. Atezolizumab versus chemotherapy in patients with platinum-treated locally advanced or metastatic urothelial carcinoma (IMvigor211): a multicentre, open-label, phase 3 randomised controlled trial. Lancet 2018; 391:748-57.

10. Ferris RL, Blumenschein G, Fayette J, Joel Guigay , A Dimitrios Colevas, Lisa Licitraet al. Nivolumab for recurrent squamous-cell carcinoma of the head and neck. N Engl J Med 2016; 375: 1856-67.

11. Ramchandren R, Domingo-Domènech E, Rueda A, Marek Trněný, Tatyana A Feldman, Hun Ju Lee et al. Nivolumab for Newly Diagnosed Advanced-Stage Classic Hodgkin Lymphoma: Safety and Efficacy in the Phase II CheckMate 205 Study. J Clin Oncol 2019; 37(23):19972007.

12. El-Khoueiry AB, Sangro B, Yau T, Todd S Crocenzi, Masatoshi Kudo, Chiun Hsu et al. Nivolumab in patients with advanced hepatocellular carcinoma (CheckMate 040): an open-label, non-comparative, phase 1/2 dose escalation and expansion trial. Lancet 2017; 389: $2492-2502$.

13. Kang Y-K, Boku N, Satoh T, Chao Y, Kato K, Chung HC,et al. Nivolumab in patients with advanced gastric or gastro-oesophageal junction cancer refractory to, or intolerant of, at least two previous chemotherapy regimens (ONO-4538-12, ATTRACTION-2): a randomized, doubled-blind, placebo-controlled, phase 3 trial. Lancet 2017; 390(10111):2461-71.

14. Wolchok JD, Chiarion-Sileni V, Gonzalez R, Rutkowski P, Grob JJ, Cowey CL, et al. Overall survival with combined nivolumab and ipilimumab in advanced melanoma. N Engl J Med 2017; 377: 1345-56.

15. Hellmann MD, Paz-Ares L, Bernabe Caro R, Bogdan Zurawski , Sang-We Kim, Enric Carcereny Costa et al. Nivolumab plus ipilimumab in advanced non-small cell lung cáncer. N Engl J Med 2019:381(21):2020-31.

16. Bertrand A, Kostine M, Barnetche T, Marie-Elise Truchetet, Thierry Schaeverbeke. Immune related adverse events associated with anti CTLA-4 antibodies: systematic review and meta-analysis. BMC Med 2015; 13: 1-14.

17. Parakh S, Cebon J, Klein O. Delayed autoimmune toxicity occurring several months after cessation of anti PD-1 therapy. Oncologist 2018; 23: 849-51.

18. Leonardi GC, Gainor JF, Altan M, Sasha Kravets, Suzanne E Dahlberg, Lydia Gedmintas et al. Safety of programmed death-1 pathway inhibitors among patients with non-small-cell lung cancer and preexisting autoimmune disorders. J Clin Oncol 2018; 36:1905-12. 
19. Johnson DB, Sullivan RJ, Ott PA, Matteo S Carlino, Nikhil I Khushalani, Fei Ye et al. Ipilimumab therapy in patients with advanced melanoma and preexisting autoimmune disorders. JAMA Oncol 2016; 2: 234-40.

20. Danlos FX, Voisin AL, Dyevre V, Jean-Marie Michot, Emilie Routier, Laurent Taillade et al. Safety and efficacy of anti-programmed death 1 antibodies in patients with cancer and pre-existing autoimmune or inflammatory disease. Eur J Cancer 2018; 91 : 21-9.

21. Coureau M, Meert A-P, Berghmans T, Grigoriu B. Efficacy and Toxicity of immune-checkpoint inhibitors in patients with preexisting autoimmune disorders. Front Med 2020; 7: 137.

22. Khan SA, Pruitt SL, Xuan L, Gerber DE. Prevalence of autoimmune disease among patients with lung cancer: implications for immunotherapy treatments options. JAMA Oncol 2016; 2: 1507-8.

23. Menzies AM, Johnson DB, Ramanujam S, V G Atkinson, A N M Wong, J J Parket al. Anti-PD-1 therapy in patients with advanced melanoma and preexisting autoimmune disorders or major toxicity with ipilimumab. Ann Oncol 2017; 28: 368-76. 